\title{
Is diamond depth distribution systematic?
}

\author{
P. NIMIS ${ }^{1 *}$, R. PRESTON ${ }^{2}$, S. PERRITT ${ }^{2}$, I. CHINN $^{2}$
}

${ }^{1}$ Dipartimento di Geoscienze, Università di Padova, Italy

${ }^{2}$ De Beers Exploration, South Africa

The thermobarometric analysis of inclusions in lithospheric diamonds indicates that they originated from a wide range of depths, with a global mode at ca. $170 \pm 15 \mathrm{~km}$ [1]. Studies based on diamond depth distribution at global scale, however, cannot clarify if this mode reflects a real concentration of diamonds, preferential sampling of materials from this level by rising kimberlites, or even a statistical distribution within the hard limits imposed by diamond stability, lithosphere thickness, and mantle adiabat under typical cratonic thermal regimes. We addressed this problem by comparing depth distributions for peridotitic diamonds from the three localities that have been the most prolific for diamond geobarometry (Cullinan, Kimberley and Voorspoed, South Africa) with those of mantle xenocrysts from the same kimberlite sources.

P-T estimates indicate that the diamonds were formed at $\mathrm{T}$ higher, equal or lower than the ambient geotherm. They may record old mantle thermal regimes or local thermal perturbations related to infiltration of parent fluids or melts. Nonetheless, the diamonds show similar depth distributions for different localities, with a distinct mode at $\sim 175 \pm 10 \mathrm{~km}$. The similarity of these distributions with that calculated for peridotitic diamonds worldwide, as well as the lack of systematic correlation with kimberlite sampling efficiency as recorded by mantle xenocrysts, suggests that this mode has genetic significance.

Based on observed depth distributions at both local and global scale and on thermodynamic modeling of $\mathrm{COH}$ fluids, diamond-forming processes are predicted to become less efficient with decreasing depth from at least $\sim 160 \mathrm{~km}$. In addition, diamond endowment near the base of the lithosphere may be negatively affected by infiltration of carbon-undersaturated melts. Considering the poor correlation between diamond and xenocryst depth distributions in single kimberlites or kimberlite clusters, even limited xenocryst records from diamond favorable depths (especially the 160-190 km interval) may correspond to significant diamond potential.

[1] Stachel (2014) Min. Ass. Canada Short Course 44, 1-28. 